\title{
An unexpected vestigial protein complex reveals the evolutionary origins of an s-triazine catabolic enzyme
}

Received for publication, January 24, 2018, and in revised form, February 28, 2018 Published, Papers in Press, March 9, 2018, DOI 10.1074/jbc.RA118.001996

Lygie Esquirol $^{\ddagger \S 1}$, Thomas S. Peat ${ }^{\Uparrow 1}$, Matthew Wilding ${ }^{\S \uparrow 1}$, Jian-Wei Liu ${ }^{\ddagger}$, Nigel G. French ${ }^{\ddagger}$, Carol J. Hartley $^{\ddagger}$, Hideki Onagi ${ }^{\S}$, Thomas Nebl" , Christopher J. Easton ${ }^{\S}$, Janet Newman", and Colin Scott ${ }^{\sharp \| 2}$

From the ${ }^{\ddagger}$ Biocatalysis and Synthetic Biology Team and ${ }^{\|}$Synthetic Biology Future Science Platform, CSIRO Land and Water, Canberra, Australian Capital Territory 2601, the ${ }^{\S}$ Research School of Chemistry, Australian National University, Canberra, Australian Capital Territory 2601, and "CSIRO Biomedical Manufacturing, Parkville, Melbourne, Victoria 3052, Australia

Edited by Karin Musier-Forsyth

Cyanuric acid is a metabolic intermediate of $s$-triazines, such as atrazine (a common herbicide) and melamine (used in resins and plastics). Cyanuric acid is mineralized to ammonia and carbon dioxide by the soil bacterium Pseudomonas sp. strain ADP via three hydrolytic enzymes (AtzD, AtzE, and AtzF). Here, we report the purification and biochemical and structural characterization of AtzE. Contrary to previous reports, we found that AtzE is not a biuret amidohydrolase, but instead it catalyzes the hydrolytic deamination of 1-carboxybiuret. X-ray crystal structures of apo AtzE and AtzE bound with the suicide inhibitor phenyl phosphorodiamidate revealed that the AtzE enzyme complex consists of two independent molecules in the asymmetric unit. We also show that AtzE forms an $\alpha 2 \beta 2$ heterotetramer with a previously unidentified 68-amino acid-long protein (AtzG) encoded in the cyanuric acid mineralization operon from Pseudomonas sp. strain ADP. Moreover, we observed that AtzG is essential for the production of soluble, active AtzE and that this obligate interaction is a vestige of their shared evolutionary origin. We propose that AtzEG was likely recruited into the cyanuric acid-mineralizing pathway from an ancestral glutamine transamidosome that required protein-protein interactions to enforce the exclusion of solvent from the transamidation reaction.

The presence of anthropogenic compounds in the environment provides selection pressures that can lead to the evolution of new metabolic pathways (1). One of the most well-studied examples of an evolutionary response by bacteria to the presence of synthetic xenobiotics is that of the $s$-triazines (2). This family of compounds includes fertilizers (e.g. atrazine and ametryn), resins and plastics (e.g. melamine), explosives (e.g. Royal Detonation Explosive), and disinfectants (e.g. cyanuric acid). Interestingly, many of the $s$-triazine catabolic pathways that have evolved share a common structure, in which specific

The authors declare that they have no conflicts of interest with the contents of this article.

This article was selected as one of our Editors' Picks.

This article contains Figs. S1-S3 and Tables S1-S3.

The atomic coordinates and structure factors (codes 6C62 and 6C6G) have been deposited in the Protein Data Bank (http://wwpdb.org/).

${ }^{1}$ Both authors contributed equally to this work.

${ }^{2}$ To whom correspondence should be addressed: CSIRO Land and Water, Foundation Bldg., Black Mountain Science and Innovation Park, Canberra, ACT 2601, Australia. E-mail: colin.scott@csiro.au. "upper pathways" convert different $s$-triazines to cyanuric acid (1,3,5-triazine-2,4,6-triol) by hydrolysis of the three substituents that decorate the heterocyclic ring (3-5). A common "lower pathway" then mineralizes cyanuric acid to carbon dioxide and ammonia.

The best characterized of the bacterial catabolic pathways that have evolved in response to $s$-triazines in the environment is the atrazine mineralization pathway of Pseudomonas sp. strain ADP. This soil bacterium was isolated in the mid-1990s by Wackett and co-workers (6). The atrazine catabolism pathway of Pseudomonas sp. strain ADP is composed of six hydrolases encoded by genes on a self-transmissible plasmid (pADP1) (5). The upper pathway (Fig. $1 A$ ) is composed of three hydrolytic steps: dechlorination, followed by two sequential $N$-alkyl chain hydrolyses. The upper pathway is catalyzed by AtzA (4, 7), AtzB (8), and AtzC (9), respectively; all three enzymes are metalloenzymes of the amidohydrolase superfamily $(9,10)$.

The lower pathway from Pseudomonas sp. strain ADP (Fig. $1 B$ ) is also composed of three hydrolases: AtzD, AtzE, and AtzF. Unlike the upper pathway, these three enzymes are serine hydrolases; AtzD is an unusual Ser-Lys hydrolase and is the archetype of a recently discovered protein fold (the Toblerone fold $(11,12)$ ), whereas AtzE and AtzF are Ser-cis-Ser-Lys hydrolases $(1,13)$. The lower pathway progresses via the AtzD-mediated ring opening of cyanuric acid to form an unstable product, 1-carboxybiuret, which is known to spontaneously decarboxylate to biuret in an aqueous environment (1). It was therefore thought that the proceeding catabolic steps consisted of the deamination of biuret by AtzE to form allophanate, and allophanate deamination by AtzF to form carbamic acid. Interestingly, these enzymatic products are unstable in an aqueous environment and can undergo spontaneous reactions; allophanate decarboxylates to urea (14), whereas carbamic acid decomposes to ammonia and carbon dioxide in water $(13,15)$. AtzD and AtzF have been overproduced in heterologous expression systems, which has allowed them to be studied biochemically $(14-17)$ and structurally $(11-13,18)$. However, expression and purification of AtzE in a heterologous system have been challenging (1), and structural and biochemical data had not been obtained previously.

The lower pathway has a degree of plasticity in its composition. AtzD can be replaced by homologs, such as TrzD from Pseudomonas sp. strain NRRLB-12227 (56\% identity to AtzD 
A. Atrazine catabolism: upper pathway

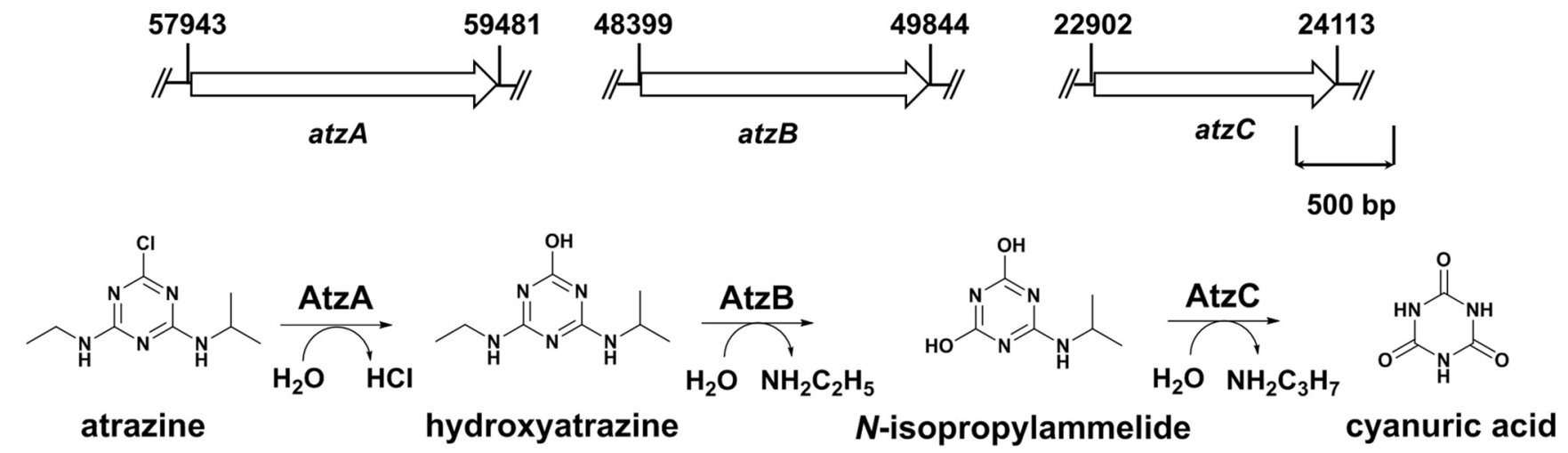

\section{B. Atrazine catabolism: lower pathway}

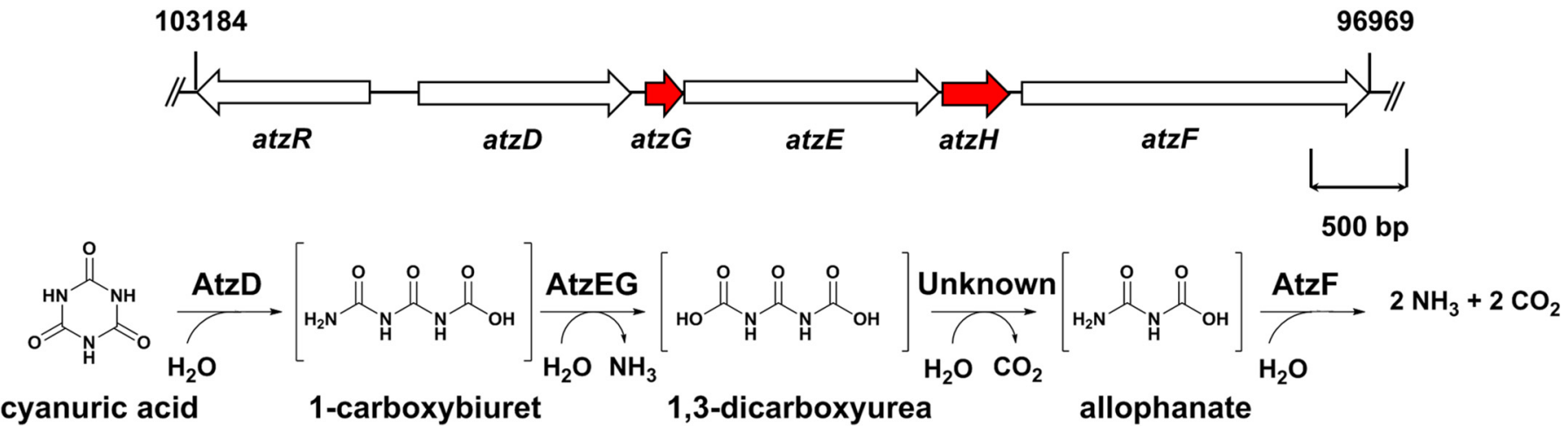

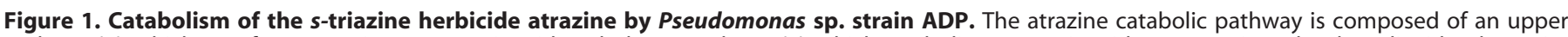

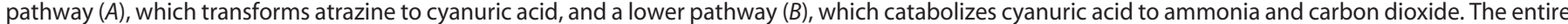

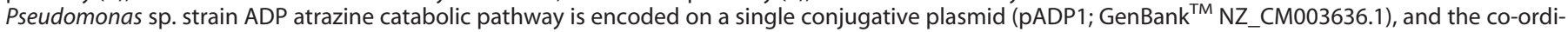

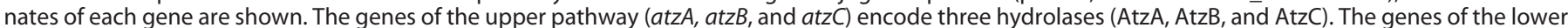

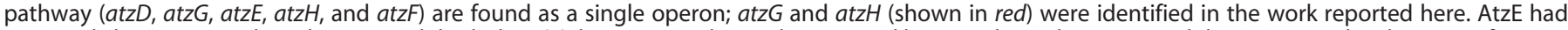

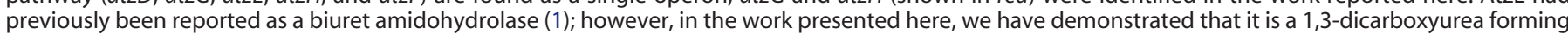
1-carboxybiuret amidohydrolase (as shown in the updated lower pathway).

$(16,17))$. AtzF is sometimes substituted by the homologous TrzF found in Enterobacter cloacae strain 99 (70\% identity to AtzF (14)), and AtzE has been replaced with the nonhomologous biuret amidohydrolase $\left(\mathrm{BiuH},{ }^{3}\right.$ a $(\beta / \alpha)_{8}$ TIM barrel cysteine hydrolase) in Rhizobium leguminasorum bv. viciae 3841 (Table 1) $(1,19)$.

Herein, we describe the purification and biochemical and structural characterization of AtzE directly from the model organism Pseudomonas sp. strain ADP. We show that AtzE forms a stable $\alpha_{2} \beta_{2}$ heterotetramer with a previously unknown small protein, AtzG, that is required for soluble expression of AtzE. Co-expression of AtzE and AtzG in Escherichia coli allows, for the first time, the heterologous overproduction of AtzE.

\footnotetext{
${ }^{3}$ The abbreviations used are: BiuH, biuret hydrolase; $\mathrm{BAH}$, barbituric acid hydrolase; CFE, cell-free extract; bis-tris, 2-[bis(2-hydroxyethyl) amino]-2-(hydroxymethyl)propane-1,3-diol; PPDI, phenyl phosphorodiamidate; PDB, Protein Data Bank; GDH, glutamate dehydrogenase; FDR, false discovery rate; MM-PBSA, Molecular Mechanics Poisson-Boltzmann Surface Area; $\mathrm{AS}$, ammonium sulfate; $\mathrm{CV}$, column volume; $\mathrm{MRM}$, multiple reaction monitoring; $\mathrm{MD}$, molecular dynamics.
}

\section{Results}

\section{AtzE is a 1-carboxybiuret hydrolase}

We attempted to produce active AtzE recombinantly in $E$. coli but were unsuccessful (consistent with previous attempts; see Refs. 1, 18). As heterologous expression was unsuccessful, we purified native AtzE from Pseudomonas sp. strain ADP. The expression of the atzDEF operon is induced under low nitrogen conditions in the presence of cyanuric acid (5), and so we cultured Pseudomonas sp. strain ADP on a minimal medium and supplied cyanuric acid as the sole nitrogen source. We were able to detect cyanuric acid amidohydrolase and allophanate amidohydrolase activities in the cell-free extracts (CFE) of these cultures. Cyanuric acid added to the CFE was mineralized (i.e. three molecules of ammonia were formed for each molecule of cyanuric acid added). However, we were unable to detect any biuret hydrolysis.

We were able to detect and follow AtzE during CFE fractionation and purification by measuring ammonia production when supplementing fractions with purified AtzD and cyanuric acid. Although the cruder samples during fractionation had 


\section{Evolution of AtzE, a 1-carboxybiuret hydrolase}

\section{Table 1}

Steady-state kinetic parameters for AtzE

The structures of the substrates and nonsubstrates tested (biuret, malonamide, asparagine, glutamine, lysine, citrulline and 2-amino-3-ureidopropionic acid) are shown in Table S2. The standard errors for the $K_{m}$ and $k_{\text {cat }}$ values are given.

\begin{tabular}{|c|c|c|c|c|}
\hline Enzyme & Substrate & $k_{\text {cat }}$ & $K_{m}$ & $k_{\text {cat }} / K_{m}$ \\
\hline & & $s^{-1}$ & $\mu M$ & $s^{-1} \cdot M^{-1}$ \\
\hline AtzD & Cyanuric acid & $17.0 \pm 1.7$ & $350 \pm 42$ & $4.8 \times 10^{4}$ \\
\hline $\mathrm{BiuH}$ & Biuret & $11.5 \pm 0.2$ & $80 \pm 7$ & $1.5 \times 10^{5}$ \\
\hline AtzE (Pseudomonas sp. ADP) & 1-Carboxybiuret & $15.5 \pm 0.1$ & $63 \pm 3$ & $2.5 \times 10^{5}$ \\
\hline \multirow[t]{4}{*}{$\operatorname{AtzE}($ E. coli $)$} & 1-Carboxybiuret & $14.1 \pm 0.2$ & $61 \pm 3$ & $2.3 \times 10^{5}$ \\
\hline & 1-Nitrobiuret & $9.4 \pm 3.3$ & $785 \pm 217$ & $1.2 \times 10^{4}$ \\
\hline & 1-Carboxymalonamide & $7.0 \pm 0.1$ & $167 \pm 17$ & $4.2 \times 10^{4}$ \\
\hline & $\begin{array}{l}\text { Succinamic acid } \\
\text { Sullo }\end{array}$ & $19.0 \pm 0.4$ & $523 \pm 30$ & $3.6 \times 10^{4}$ \\
\hline
\end{tabular}

high background levels of ammonia, additional ammonia produced from cyanuric acid by AtzD and AtzE was distinguishable from this background. Using ammonia production as a proxy for enzyme activity, we were able to isolate $0.125 \mathrm{mg}$ of pure AtzE per liter of Pseudomonas sp. strain ADP culture via ammonium sulfate precipitation and four chromatography steps (Fig. S1A and Table S1).

The mass of the isolated protein was 48,119 Da by MS, consistent with the predicted mass of AtzE, and the fragmentation pattern obtained by tryptic digest confirmed that the isolated protein was AtzE. Differential scanning fluorimetry revealed that the melting temperature $\left(T_{m}\right)$ for AtzE isolated from Pseudomonas sp. strain ADP was greater than $60^{\circ} \mathrm{C}$. Previous reports had suggested that AtzE could not be produced in $E$. coli because of low stability (1); however, the high $T_{m}$ of purified AtzE suggested that the poor expression of AtzE in E. coli was not due to protein instability.

Purified AtzE had no detectable biuret aminohydrolase activity under any condition tested. However, AtzE-mediated ammonia production was observed when incubated with cyanuric acid and pure AtzD. This suggested that the product of cyanuric acid hydrolysis by AtzD, 1-carboxybiuret, was in fact the natural substrate for AtzE. LC-MS was subsequently used to follow the reactions directly. There was no detectable biuret amidohydrolase activity with AtzE (Fig. $2 A$ ), but it was detected using the biuret amidohydrolase from a Rhizobium species, BiuH (Fig. 2B) (19). Moreover, biuret accumulates in reactions in which cyanuric acid is treated with AtzD (Fig. 2C), but it does not when AtzE is also included (Fig. 2D), suggesting that AtzE prevents biuret's formation via the hydrolytic deamination of 1-carboxybiuret.

Steady-state kinetic data for AtzD, AtzE, and the biuret hydrolase were obtained (Table 1 ). The product inhibition of AtzD reported previously (11) was alleviated by the addition of AtzE, allowing the determination of rates at concentrations above $0.2 \mathrm{~mm}$ cyanuric acid for the first time. The kinetic parameters determined for AtzD were found to be a $k_{\text {cat }}$ of 17 $\mathrm{s}^{-1}$, a $K_{m}$ of $350 \mu \mathrm{M}$, and a $k_{\text {cat }} / K_{m}$ of $4.8 \times 10^{4} \mathrm{~s}^{-1} \cdot \mathrm{M}^{-1}$. The steady-state kinetic parameters for AtzE were found to be similar to those of the Rhizobium biuret amidohydrolase for its physiological substrate, with a $k_{\text {cat }}$ of $16 \mathrm{~s}^{-1}$, a $K_{m}$ of $63 \mu \mathrm{M}$, and a $k_{\text {cat }} / K_{m}$ of $2.5 \times 10^{5} \mathrm{~s}^{-1} \cdot \mathrm{M}^{-1}$ for AtzE, and a $k_{\text {cat }}$ of $12 \mathrm{~s}^{-1}$, a $K_{m}$ of $80 \mu \mathrm{M}$, and a $k_{\text {cat }} / K_{m}$ of $1.5 \times 10^{5} \mathrm{~s}^{-1} \cdot \mathrm{M}^{-1}$ for BiuH (Table 1 ).

We also tested AtzE with a number of potential additional substrates, including the product of barbituric acid hydrolase (1-carboxymalonamide), analogs of AtzE's natural substrate (1-nitrobiuret and succinamic acid), structurally related $\alpha$ amino acids (citrulline, lysine, glutamine, asparagine, and 2-amino-3-propionic acid) and the biuret analog malonamide (Table 1 and Table S2). None of the $\alpha$-amino acids were substrates for AtzE nor was the biuret analog malonamide (Table S2). However, 1-carboxymalonamide, 1-nitrobiuret, and succinamic acid were all substrates for AtzE with $k_{\text {cat }} / K_{m}$ values of $4.2 \times$ $10^{4}, 1.2 \times 10^{4}$, and $3.6 \times 10^{4} \mathrm{~s}^{-1} \cdot \mathrm{M}^{-1}$, respectively (Table 1 ; Fig. 3).

LC-MS was used to identify that the product of AtzE-mediated hydrolysis of 1-carboxymalonamide is 1-carboxymalonamic acid through hydrolysis of the terminal amine. Succinamic acid has a terminal amide rather than a ureido group, suggesting that AtzE hydrolyzes the amide from this substrate in an equivalent reaction to that of the hydrolysis of 1-carboxymalonamide. We therefore propose an update to the cyanuric acid catabolic pathway, in which AtzE acts as a 1-carboxybiuret amidohydrolase, producing 1,3-dicaboxyurea and ammonia (Figs. $1 B$ and $2 D$ ).

\section{Structure of AtzE reveals the presence of an unexpected but essential ancillary protein}

X-ray crystal structures were obtained for purified AtzE (PDB code 6C62; Table 2), and purified AtzE was treated with the suicide inhibitor phenyl phosphorodiamidate (PPDI; PDB code 6C6G; Table 2). The crystals of AtzE had two independent molecules of AtzE in the asymmetric unit, and the entire chain could be traced for both molecules (Fig. 4). Surprisingly, after positioning the AtzE chains in the structure, additional protein density was observed (Fig. 4). The density was of high enough quality to allow for initial estimation of the unknown sequence, which was identical to the predicted translation product of a short (204 bp) unannotated intergenic region between atzD and $a t z E$ in the atzDEF operon on the pADP1 plasmid (Fig. $1 B$ ).

Examination of purified AtzE by SDS-PAGE indicated a small co-purified protein of approximately the same size as the protein that co-crystallized with AtzE (Fig. S1B). Mass spectrometry of the AtzE purified from Pseudomonas confirmed the presence of an unidentified protein having a mass of $7422 \mathrm{Da}$ (Fig. S1C and Table S3), and analysis of tryptic fragments of the 7.4-kDa protein confirmed that it was encoded by the small unannotated ORF located between the $a t z D$ and $a t z E$ genes (Fig. S2), which we have termed atzG (Fig. S1). Along with the two molecules of AtzE, there are two molecules of AtzG in the asymmetric unit (Fig. 4B). 
A.

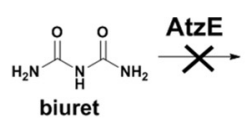

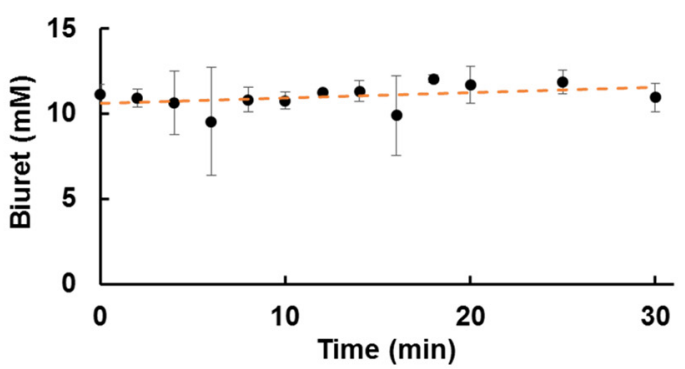

C.

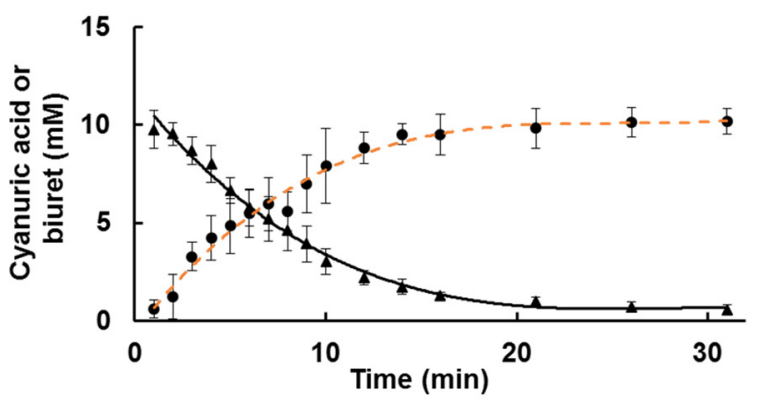

B.
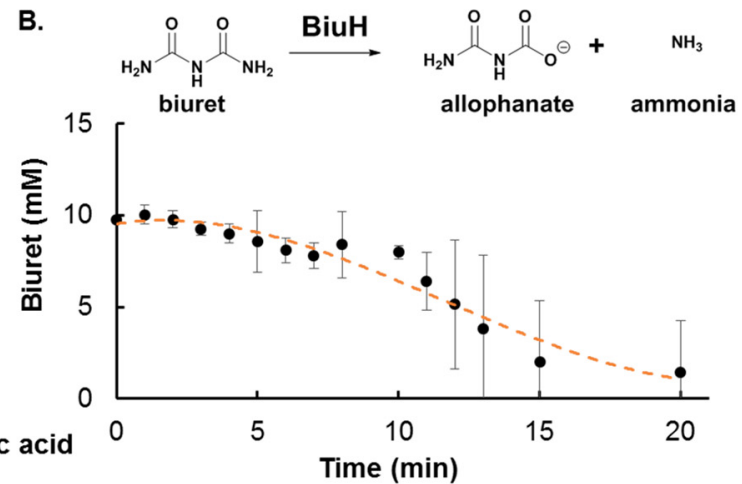

Biuret

Figure 2. LC-MS analysis of AtzE activity with biuret and 1-carboxybiuret. The concentrations of cyanuric acid (triangles) and biuret (circles) present in each reaction are shown. Four reaction conditions were tested as follows: $A$, biuret in presence of AtzE; $B$, biuret in presence of the biuret hydrolase BiuH; $C$, cyanuric acid in presence of AtzD; and D, cyanuric acid in presence of AtzD and AtzE. Reactions were done in triplicate, and the standard deviations are shown.

(1)<smiles>O=C1NC(=O)C(=O)N1</smiles>

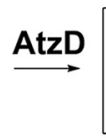

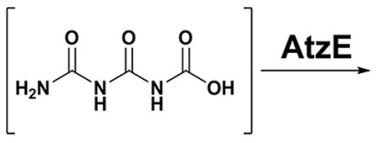

cyanuric acid 1-carboxybiuret<smiles>[BiH3]</smiles><smiles>NC(=O)CC(=O)NC(=O)O</smiles>
barbituric acid 1-carboxymalonamide

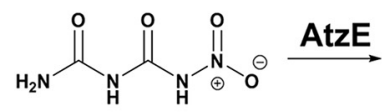

1-nitrobiuret

\section{AtzE} ammonia<smiles>O=C(O)NC(=O)NC(=O)O</smiles>

\section{1,3-dicarboxyurea}

(3)

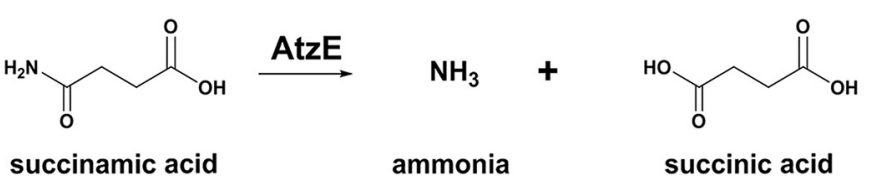

Figure 3. AtzE-dependent deamination reactions. The schemes for AtzE-dependent deamination are shown as follows: 1, 1-carboxybiuret; 2,1 -carboxymalonamide; 3, 1-nitrobiuret and 4, succinamic acid. 1-Carboxybiuret and 1-carboxymalonamide were produced in situ by cyanuric acid amidohydrolase (AtzD) and barbituric acid amidohydrolase (BAH), respectively. Square brackets indicate compounds that spontaneously decarboxylate under the reaction conditions used.

Of the protein structures available in the PDB (20), AtzE is most similar to the glutamine deaminase component (chain A; $35 \%$ sequence identity) of $4 \mathrm{WJ} 3$, a glutamine transamidosome from Pseudomonas (21); 428 residues aligned (out of 457) with a 1.5- $\AA$ root mean square deviation over the aligned backbone atoms (Fig. 5). The transamidosome is a three-protein complex (GatCAB) that is essential for the production of correctly charged tRNA in bacteria via the transfer of ammonia from 


\section{Evolution of AtzE, a 1-carboxybiuret hydrolase}

Table 2

Crystal structure parameters

Note: values in parentheses are for the highest resolution shell. NA means not applicable.

\begin{tabular}{lll}
\hline & 6C62 (Native) & 6C6G (PPDI) \\
\hline $\begin{array}{l}\text { Data collection } \\
\text { Space group }\end{array}$ & $\mathrm{I} 2$ & $\mathrm{I} 2$ \\
Cell dimensions & & \\
$\quad a, b, c(\AA)$ & $79.5,89.0,141.7$ & $78.6,88.9,141.9$ \\
$\alpha, \beta, \gamma\left({ }^{\circ}\right)$ & $90,101.9,90$ & $90,101.3,90$ \\
Resolution $(\AA)$ & $1.95(1.99-1.95)$ & $2.10(2.16-2.10)$ \\
$R_{\text {merge }}$ & $0.233(1.545)$ & $0.326(1.282)$ \\
$R_{\text {pim }}$ & $0.095(0.622)$ & $0.126(0.496)$ \\
$I / \sigma I$ & $6.9(2.1)$ & $6.7(2.0)$ \\
$C C 1 / 2$ & $0.991(0.804)$ & $0.982(0.656)$ \\
Completeness $(\%)$ & $100(100)$ & $100(100)$ \\
Redundancy & $6.9(7.1)$ & $7.6(7.6)$ \\
\hline Refinement & 2 dimers & 2 dimers \\
Resolution $(\AA)$ & $69.3-1.95$ & $69.6-2.10$ \\
Unique reflections & 66,810 & 53,225 \\
$R_{\text {work }} / R_{\text {free }}$ & $15.3 / 19.1$ & $16.7 / 21.0$ \\
No. of atoms & 8659 & 8523 \\
Protein & 7930 & 7882 \\
Inhibitor & NA & 8 \\
Water & 726 & 639 \\
$B$-Factors $\left(\AA^{2}\right)$ & 17.5 & 16.8 \\
Protein & 17.4 & 16.9 \\
Inhibitor & NA & 12.4 \\
Water & 24.6 & 21.1 \\
Root mean square deviations & & 0.014 \\
Bond lengths $(\AA)$ & 0.017 & 1.643 \\
Bond angles $\left({ }^{\circ}\right)$ & 1.726 & \\
\hline & &
\end{tabular}
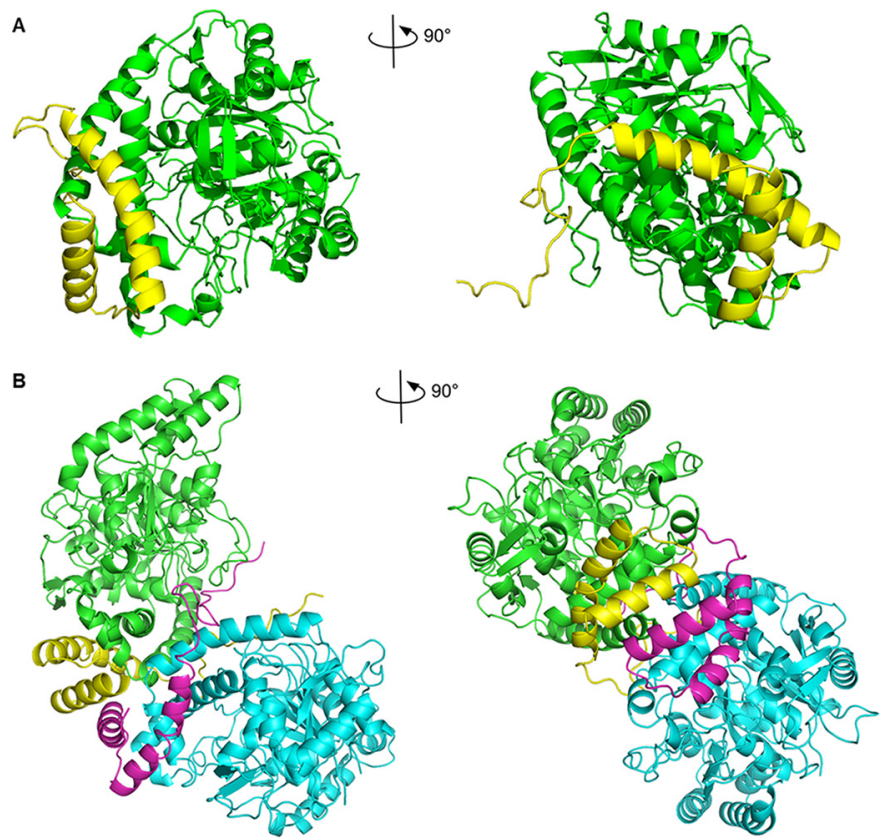

Figure 4. X-ray crystal structure of the unexpected AtzE complex. A, AtzE monomer (green) has a typical amidase fold. Surprisingly, it is associated with a small ( 68 amino acids) protein (yellow). $B, \alpha_{2} \beta_{2}$ heterotetramer, containing two molecules of AtzE (green and cyan) and two molecules of the 68-amino acid protein (yellow and magenta).

glutamine to acidic amino acid-charged tRNA (21). Deamination occurs in the active site of an amidase (GatA). The ammonia is then channeled, via an "ammonia tunnel," to a phosphateactivated, aspartate-charged tRNA in the second active site (in GatB). Channeling prevents loss of ammonia and excludes water from the active site of GatB (22).

AtzG is homologous to the GatC protein in the GatCAB complex and binds AtzE in the same position as GatC binds

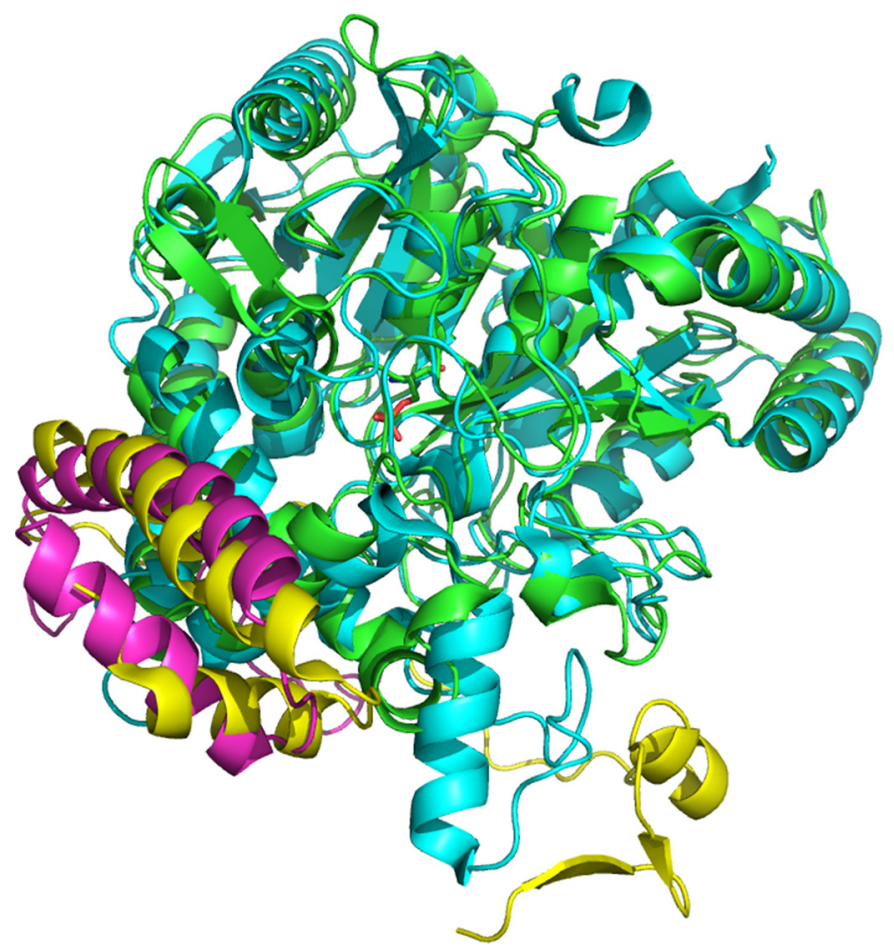

Figure 5. Superposition of the AtzEG heterodimer and the GatA-GatC complex. AtzE and AtzG are shown in green and magenta, respectively. GatA and GatC are shown in cyan and yellow, respectively. The phosphoserine from the AtzE X-ray crystal structure (Ser-174) is shown in stick representation.

GatA in the GatCAB complex. The function of GatC is to coordinate the complex by forming appropriate interactions with both GatA and GatB. AtzG appears to fulfill a similar role, gluing together the AtzE dimer resulting in a tightly associated heterotetramer. According to the program PISA (23), the AtzEG heterotetramer sequesters over $12,500 \AA^{2}$ of buried surface area, giving a $\Delta G$ of interaction of $-108 \mathrm{kcal} / \mathrm{mol}$. AtzG has extensive interactions with both AtzE and AtzG of the dimerization partner (Fig. 4). Notably, AtzG is 28 amino acids shorter than GatC (68 versus 96 amino acids), with the additional 28 amino acids of $\mathrm{GatC}$ forming the majority of its interactions with GatB (Fig. 5) (21). GatC also participates in the formation of the ammonia tunnel in the GatCAB complex. Interestingly, the ammonia tunnel is retained in AtzEG (Fig. 6). The retention of the ammonia tunnel may facilitate a highreaction rate by provide rapid egress of the ammonia product.

When AtzE and AtzG were co-expressed in E. coli, a soluble (Fig. S1B), active enzyme that was catalytically indistinguishable from AtzEG purified from Pseudomonas sp. strain ADP was obtained (Table 1). This confirmed that AtzG promotes the production of soluble, active AtzE. Notably, GatA cannot be overproduced in the absence of $\operatorname{GatC}(24,25)$.

\section{Substrate specificity and reaction mechanism}

Molecular dynamics were used to understand the behavior of 1-carboxybiuret in the active site. 1-Carboxybiuret binds via a series of hydrogen-bonding interactions: the terminal carboxylate of the substrate binds to Tyr-125, Asn-172, and Gln-402; the main chain carbonyl of Gly-126 binds the terminal adjacent amines, and the main chain $\mathrm{NH}$ of Gln-402 binds the carbonyl between those amines (Fig. 7A). The interactions with the ter- 

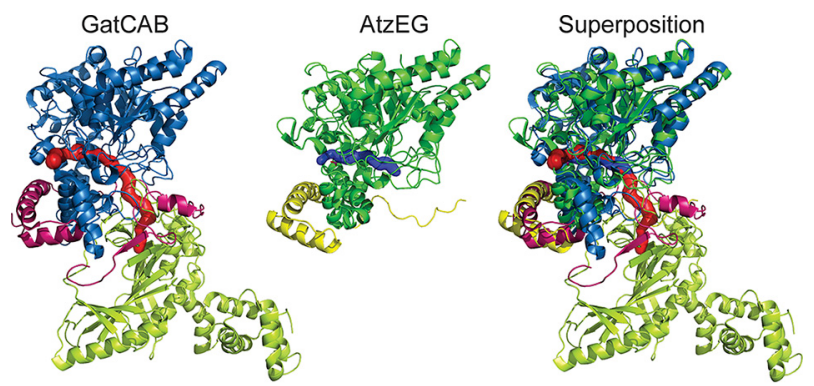

Figure 6. Conservation of the transamidosome ammonia tunnel in AtzEG. The ammonia tunnel is shown in the GatCAB complex, and a comparable tunnel is seen in AtzEG. Superposition of the two protein complexes show that the tunnels overlap for the whole length of the AtzEG tunnel. CAVER (30) was used to generate this figure.

minal carboxylate substantially strengthen the binding of 1-carboxybiuret relative to biuret and would explain the lack of activity with biuret. From a 500-ns MD simulation, we found that the $\Delta G$ total as a function of time (Fig. $7 C$ ) for 1-carboxybiuret reached significantly lower values than biuret $(-33$ and -12 $\mathrm{kcal} / \mathrm{mol}$, respectively). Carboxybiuret was retained by the AtzE active site for the duration of the simulation, whereas biuret was observed to leave the active site after $400 \mathrm{~ns}$.

The catalytic mechanism of AtzE is likely to resemble that of other enzymes with Ser-cisSer-Lys catalytic triads (e.g. malonamidase, allophanate amidohydrolase, DNA polymerase $\mathrm{V}$ accessory protein, and signal peptidase) (13, 26-28). The catalytic triad of AtzE, inferred from crystallographic data and homology with other amidases, was composed of Lys-74, cisSer-150, and Ser-174. In the substrate-docked structure, Ser174 is positioned for attack at the carbonyl of the terminal amide of 1-carboxybiuret (Fig. 7B). Moreover, extra density consistent with a phosphate group was seen associated with Ser174 in the crystal structure of AtzE treated with PPDI (PDB code $6 \mathrm{G} 6 \mathrm{C}$ ). This suggests that the phosphodiamidate moiety had been transferred to the catalytic serine (Ser-174) during the crystallization process and that Ser-174 is the nucleophilic residue in the catalytic triad. Mass spectrometry of proteolyzed PPDI-treated AtzE showed that $70 \%$ of the enzyme was labeled with monoaminophosphate at Ser-174 and 30\% with diaminophosphate. This suggests that the diaminophosphate is labile, releasing an ammonia in an aqueous solution (consistent with previous reports) (1).

There are three sets of potential reaction products from the deamination of 1-carboxybiuret: allophanate and carbamate, diacarboxyammonia and urea, or 1,3-dicarboxyurea and ammonia. These products are difficult to resolve using the GDH-coupled assay that we employed, as carbamate and diacarboxyammonia readily decompose in water to produce ammonia. As GatA produces ammonia, we might expect that AtzE does, too; furthermore, the substrate range of AtzE includes succinamic acid from which carbamate cannot be produced. We therefore propose that AtzE deaminates 1-carboxybiuret, producing 1,3-dicarboxyurea (Fig. 1B), which then monodecarboxylates to form allophanate (the substrate for AtzF) $(13,15)$. Currently, it is unclear whether the formation of allophanate is spontaneous or enzyme-mediated.

The suggested mechanism for AtzE is described in Fig. 8. In the first step, Lys-74, Ser-150, and Ser-174 all form a hydrogen bonding network, where Lys-74 acts as a general base to activate the catalytic Ser-174 through the cis-Ser-150-bridging ligand. The activated Ser-174 performs a nucleophilic attack on the terminal amide end of 1-carboxybiuret, leading to the formation of a covalent acyl-enzyme intermediate and ammonia. Lys-74 then acts as a general base, activating water and leading to the hydrolysis of the acyl enzyme, releasing 1,3-dicarboxyurea, and restoring the active site to its original state.

It is interesting that AtzE has no detectable activity with GatA substrates (e.g. $\alpha$-amino acids), given their high degree of structural similarity. We compared the structures of AtzE with docked 1-carboxybiuret and GatA with glutamine bound in its active site (Fig. 9). The AtzE active site is highly conserved when compared with that of GatA, albeit with some differences (Fig. 9). The catalytic triad is conserved (Lys-79, Ser-154, and Ser178 in GatA), as are Gly-126 (GatA Gly-130), Ser-169 (GatA Ser-173), Thr-171 (GatA Thr-175), and Gly-173 (GatA Gly177). Among the key differences between the two enzymes are Phe-127 and Tyr-125 (Gly-131 and Met-129 in GatA), which appear to stabilize 1-carboxybiuret in the AtzE active site via $\pi$-stacking interactions to the conjugated carbonyl system in the substrate. Phe- 127 would also sterically prevent the binding of glutamine and other $\alpha$-amino acids, which cannot adopt a planar orientation like 1-carboxybiuret, and therefore likely has a prominent role in substrate specificity. Additionally, Asp- 425 in GatA, which is required for hydrogen bonding to the backbone nitrogen of the substrates, is Gly-398 in AtzE.

\section{Discussion}

Previously, AtzE had been reported to be a biuret hydrolase $(1,5,14,19)$, largely through comparison with the nonhomologous biuret hydrolase of Rhizobium sp. (Table 1). However, our findings demonstrate that AtzE is a 1-carboxybiuret hydrolase and that the terminal carboxylate is essential for correct substrate binding. Sequence and structural homology suggest that AtzEG may have been "repurposed" from the bacterial glutamine transamidosome, in which a similar complex, GatAC, is essential in channeling a solvent-labile intermediate between the complex's two active sites (22). AtzG does not appear to fulfill the same complex co-ordinating function as $\mathrm{GatC}$, instead it may be that the obligate AtzEG complex is simply a vestige of their shared evolutionary past. Interestingly, Pseudomonas sp. strain ADP possesses genes that encode a predicated GatCAB complex (gatA, GenBank ${ }^{\mathrm{TM}}$ KSW28066.1; gatB, GenBank $^{\mathrm{TM}}$ KSW26274.1; gatC, KSW26275.1). However, as atzEG are encoded by a gene cluster on a transposable element, carried on a self-transmissible plasmid $(5,29)$, it seems unlikely that atzEG was recruited from this specific gene cluster.

Despite the structural and mechanistic similarities between AtzEG and its likely ancestor (a GatAC-like protein), the substrate range for AtzEG excludes the GatAC substrates asparagine and glutamine. GatCAB fulfills an essential role in the production of asparagine- and glutamine-charged tRNA at the expense of glutamine (31), and it is plausible that AtzEG rapidly evolved away from these substrates under selective pressure to eliminate perturbations in core cellular functions (i.e. aminoacyl tRNA production and amino acid pools). 

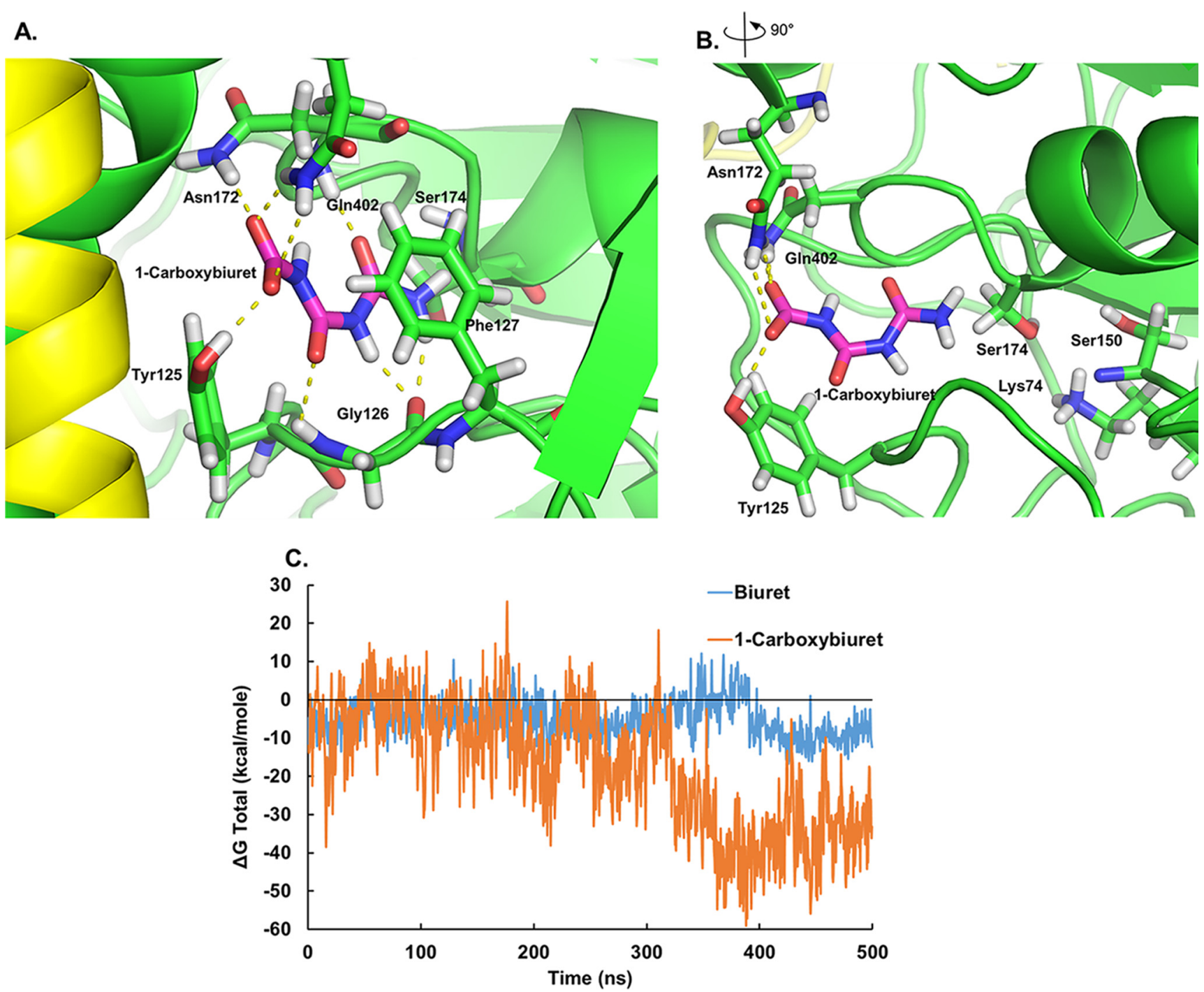

Figure 7. Docking and molecular dynamics of substrate in the AtzE active site. A, 1-carboxybiuret docked into the AtzE active site in its most stable configuration ( $\Delta G$ minimal). 1-Carboxybiuret is shown in magenta; AtzE is shown in green, and AtzG is shown in yellow. Hydrogen bonds between the protein and substrate are shown as dashed lines. $B, 90^{\circ}$ rotation of $A$ showing the position of the catalytic amino acids Ser-174, Ser-150, and Lys-74; for clarity, the stick representations of amino acids Gly-126 and Phe-127 have been removed. $C$, variation in $\Delta G(\mathrm{kcal} / \mathrm{mol})$ as a function of time (nanoseconds) during a molecular dynamics simulation of biuret and 1-carboxybiuret docked into the active site of AtzEG. The lowest $\Delta G$ total reached during the 1-carboxybiuret MM-PBSA is -59.0 at $388 \mathrm{~ns}$ of simulation, whereas the lowest $\Delta G$ total for biuret is only of -16.7 at $425 \mathrm{~ns}$ of simulation. Although 1 -carboxybiuret adopts a stable conformation over time, biuret does not and escapes the active site at $t=400 \mathrm{~ns}$.

Although not itself catalytic, AtzG is essential for correct AtzE function, and previous attempts to express AtzE in heterologous hosts were unsuccessful because the gene encoding AtzG had been overlooked by automated annotation. There is an increasing body of evidence that small, overlooked openreading frames often encode functional low-molecular-weight proteins $(32,33)$. It may be that a subset of these have structural roles, like that of AtzG, and are required to promote or enhance soluble protein expression or stability of their partner proteins.

Surprisingly, the cyanuric acid-mineralizing operon contains a second unannotated ORF between the genes encoding AtzE and AtzF (Fig. 1B) that is predicted to encode a 129-amino acid protein (GenBank ${ }^{\mathrm{TM}}$ WP_064987550.1), tentatively named AtzH, which belongs to the DUF3225 family of uncharacterized proteins. Preliminary proteomics with Pseudomonas sp. strain $\mathrm{ADP}$ indicate that AtzH is expressed under the same conditions as AtzD, -E, -F, and -G. Investigations are underway to determine the role of AtzH.

\section{Experimental procedures}

\section{Purification of AtzE from Pseudomonas sp. strain ADP}

Pseudomonas sp. strain ADP's growth conditions were optimized to induce expression of the cyanuric acid catabolism operon. 40 liters of Pseudomonas sp. strain ADP was grown in $500-\mathrm{ml}$ cultures in 2-liter flasks. Cultures were grown in minimal medium at $28^{\circ} \mathrm{C}$ and shaken at $200 \mathrm{rpm}$ until an $\mathrm{OD}_{600}$ of 0.4 was reached. The minimal medium contained $10 \mathrm{~mm}$ cyanuric acid as a sole nitrogen source, $26 \mathrm{~mm} \mathrm{Na}_{2} \mathrm{HPO}_{4}, 22 \mathrm{~mm}$ $\mathrm{KH}_{2} \mathrm{PO}_{4}, 8.5 \mathrm{~mm} \mathrm{NaCl}, 200 \mu \mathrm{M} \mathrm{MgSO}_{4}, 2.9 \mathrm{~mm}$ sucrose, $3.4 \mathrm{~mm}$ trisodium citrate, $44 \mu \mathrm{M} \mathrm{CaCl}_{2}, 20 \mathrm{ml} /$ liter of vitamin stock, and $1 \mathrm{ml} /$ liter of trace elements, adapted from Balotra et al. (13). The cells were harvested by centrifugation $(8000 \times g$ for 15 


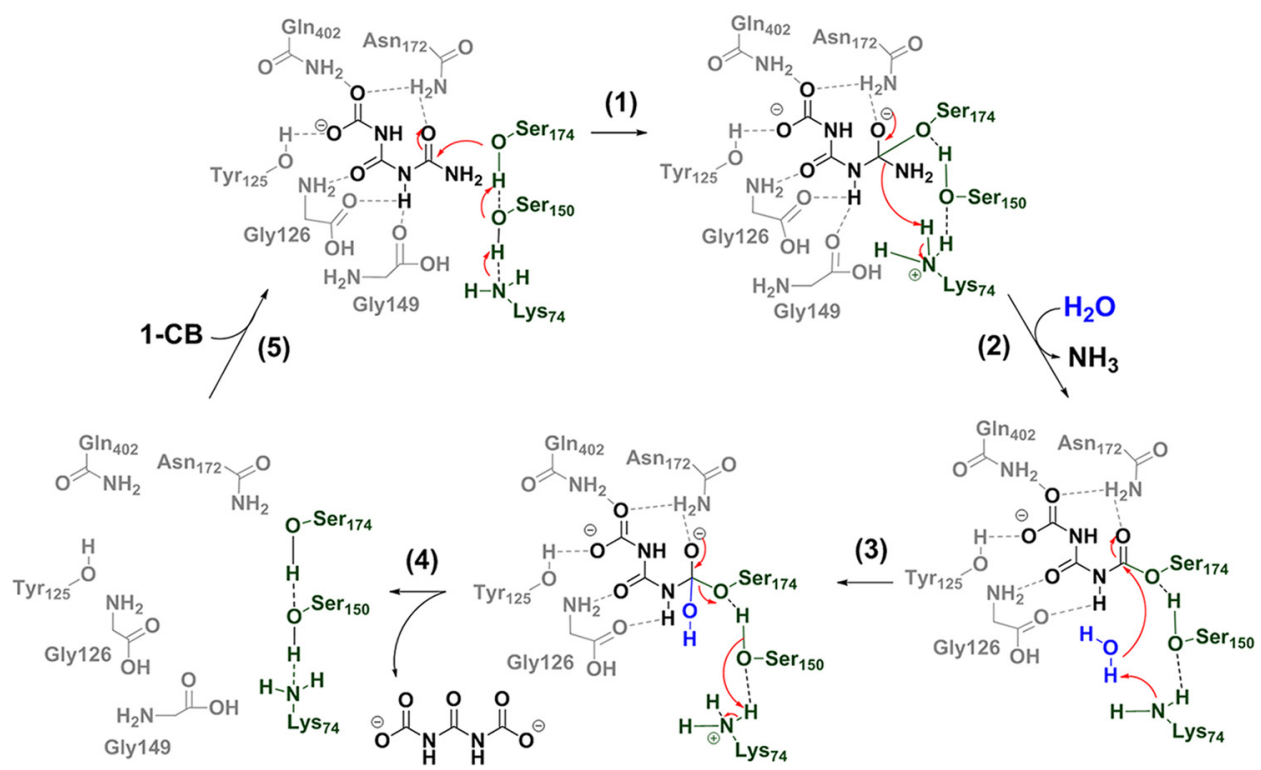

Figure 8. AtzE reaction mechanism. The catalytic triad (Lys-74, Ser-150, and Ser-174; shown in green) forms a hydrogen-bonding network with the substrate; Lys-74 activates the catalytic (Ser-174) via the cis-Ser-150-bridging ligand. Ser-174 performs a nucleophilic attack on the terminal amide of the substrate, forming the covalent acyl-enzyme intermediate and releasing ammonia. Lys-74 then acts as a general base, activating water (blue) and leading to the hydrolysis of the acyl enzyme, releasing 1,3-dicarboxyurea and regenerating the active site.
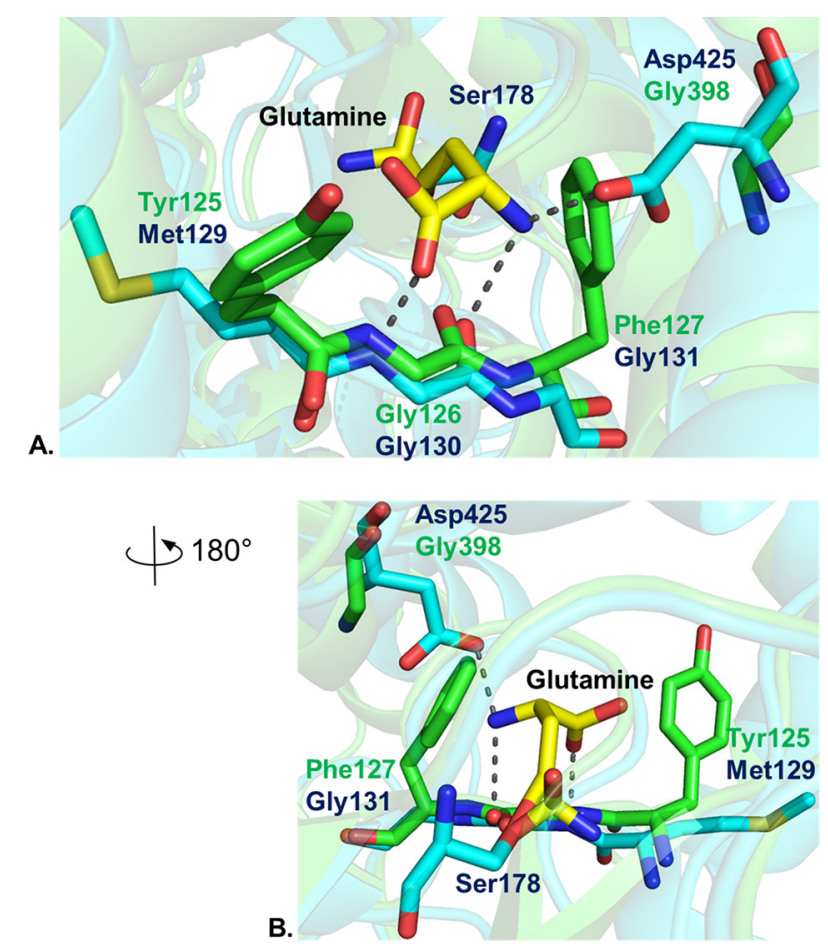

Figure 9. Comparison of the active sites of AtzE and GatA bound to 1-carboxybiuret and glutamine, respectively. The AtzE active site (green) is shown superposed on the GatA active site (cyan). The GatA substrate (glutamine; yellow) is also shown. Hydrogen bonds between GatA and glutamine are shown as dotted lines. $A$ and $B$ are rotated $180^{\circ}$ relative to each other to highlight the positions of the $\alpha$-amine of glutamine and Phe-127 in AtzE.

min) and lysed as described in Ref. 13, and the soluble supernatant was used for further purification.

AtzE was purified by a four-step purification process: ammonium sulfate (AS) precipitation, followed by hydrophobic interaction, anion-exchange and size-exclusion chromatography. A solution of concentrated AS was added to the supernatant to give a final concentration of $0.6 \mathrm{M}$ and stirred for $4 \mathrm{~h}$ at $4{ }^{\circ} \mathrm{C}$.
After centrifugation $(18,000 \times g$ for $30 \mathrm{~min})$, the soluble fraction was syringe-filtered through a $0.22-\mu \mathrm{m}$ filter.

The supernatant from the AS cut was purified by hydrophobic interaction chromatography using a 65-ml column packed with phenyl-Sepharose preparation-grade resin (GE Healthcare), equilibrated with $25 \mathrm{~mm}$ potassium phosphate and $0.6 \mathrm{M}$ ammonium sulfate, $\mathrm{pH}$ 7.5. After running 4 column volumes (CV) of $0.4 \mathrm{M} \mathrm{AS}$, a reverse gradient from 0.4 to $0.09 \mathrm{M}$ AS over $10 \mathrm{CV}$ was used to elute the protein. Fractions containing a 48-kDa band (SDS-PAGE) eluted between 0.27 and $0.14 \mathrm{~m}$ AS. These fractions were pooled and concentrated to $10 \mathrm{ml}$ volume (Amicon Ultra-15 centrifugal filter unit, Ultracel-30 membrane). A desalting step was performed using a 53-ml HiPrep C26/10 desalting column (GE Healthcare), equilibrated with 25 mM potassium phosphate, $\mathrm{pH} 8.5$, for $1.5 \mathrm{CV}$.

The crude protein fraction was purified by anion-exchange chromatography using a 77-ml column packed with Q-Sepharose preparation grade resin (GE Healthcare), equilibrated with $25 \mathrm{~mm}$ potassium phosphate, $\mathrm{pH}$ 8.5. The protein was eluted with a gradient of $0-0.25 \mathrm{M} \mathrm{NaCl}$ over $11 \mathrm{CV}$. Fractions eluted between 0.16 and $0.23 \mathrm{M} \mathrm{NaCl}$ were found to contain a $48-\mathrm{kDa}$ band (SDS-PAGE). After pooling, these fractions were concentrated to $12 \mathrm{ml}$ using an Amicon Ultra-15 centrifugal filter unit.

This combined sample was applied to a 130 -ml size-exclusion column packed with Superdex 200 preparation grade resin (GE Healthcare), equilibrated with $25 \mathrm{~mm}$ potassium phosphate and $200 \mathrm{~mm} \mathrm{NaCl}, \mathrm{pH} 7.5$, and eluted over $1.5 \mathrm{CV}$ with the same buffer. All chromatography steps were performed using an ÄKTA purifier UPC 10 (GE Healthcare).

\section{Cloning}

A synthetic version of the atzE gene, coding for the protein NP_862538 (NP_862538.1), was obtained from GenScript Corp. (Piscataway, NJ), inserted into pUC57, and flanked by the restriction sites NdeI and BamHI. The genes were subcloned 


\section{Evolution of AtzE, a 1-carboxybiuret hydrolase}

into the NdeI and BamHI sites of pETcc2, described in Peat et al. (11). Following the lack of soluble AtzE expression, we reamplified atzE flanked with $\mathrm{NcoI}$ and AvrII with the primers $\left(5^{\prime}\right.$ to 3': GTACACCCATGGGAATGAAGACAGTAGAAATTATTGAAGG and TTTTTTGAGCTCCCACATTTCAGTCGGGCGATAC). atz $E$ was subcloned into the first multiple cloning site of the pACYCDuet-1 vector (Novagen), a low copy number expression vector for co-expression of two genes, with an inframe $\mathrm{N}$-terminal thrombin-cleavable $\mathrm{His}_{6}$ tag. AtzG coding for the protein WP_082996223 (WP_082996223.1) was cloned directly from Pseudomonas sp. ADP genomic DNA with the primers (5' to 3': CGACGACATATGCTCGAGATGACGGAAACTG and TGCTGCGAGCTCCCTAGGTCAGATATCTTCTGC), before being subcloned into the second cloning site of the pACYCDuet-1 vector using the enzymes NdeI and XhoI.

The atzD coding for the protein NP_862537 (NP_862537.1) had been cloned into pETcc 2 previously $(11,13,18)$. Ligations were performed using $\mathrm{T}_{4}$ ligase. Restriction enzymes and $\mathrm{T}_{4}$ ligase were obtained from Thermo Fisher Scientific. The biuret hydrolase from $R$. leguminasorum bv. viciae 3841 (BiuH) (AM236084.1) and barbituric acid hydrolase from Nocardioides sp. JS614 coding for the protein ABL81019 (ABL81019.1) were expressed in E. coli as described elsewhere $(12,19)$.

\section{Heterologous protein expression}

The expression vectors were used to transform E. coli BL21 $(\lambda \mathrm{DE} 3)$ cells (Invitrogen). Bacteria were grown on LuriaBertani (LB) medium containing $100 \mu \mathrm{g} / \mathrm{ml}$ ampicillin for the pETcc 2 constructs or $34 \mu \mathrm{g} / \mathrm{ml}$ chloramphenicol for the pACYCDuet-1 construct. Cells were grown with shaking at 200 $\mathrm{rpm}$ at $28^{\circ} \mathrm{C}$. Protein expression was induced at an $\mathrm{OD}_{600}$ of 0.8 by addition of isopropyl $\beta$-D-1-thiogalactopyranoside (1 $\mathrm{mm}$ final concentration).

Cells were harvested $24 \mathrm{~h}$ after induction by centrifugation at $5000 \times g$ for 15 min using an Aventi J-E centrifuge (Beckman Coulter, Indianapolis, IN), resuspended in lysis buffer (25 mM potassium phosphate, $5 \mathrm{~mm}$ imidazole, $\mathrm{pH}$ 7.5), and lysed by passage through a Microfluidics homogenizer M-110P five times at 15,000 p.s.i. The lysis was followed by centrifugation at $18,000 \times g$ for 45 min to pellet the cellular debris, and the soluble fraction was used for further purification.

The soluble fraction was syringe-filtered throughout a $0.22-\mu \mathrm{m}$ filter. The filtrate was purified using a $5-\mathrm{ml}$ nickelnitrilotriacetic acid superflow cartridge (Qiagen) with a gradient from $5 \mathrm{~mm}$ imidazole to $500 \mathrm{~mm}$ over $10 \mathrm{CV}$. SDS-polyacrylamide gel analysis was performed to assess the purity of the fractions.

\section{Enzyme assays}

Cyanuric acid hydrolysis by AtzD was followed by UV spectrophotometry at $214 \mathrm{~nm}$ (13) using 0-0.6 mM cyanuric acid in 25 mм phosphate buffer, pH 9.

A GDH (Sigma-Aldrich)-coupled reaction was used to measure ammonia release and determine the activity rate in the $\mathrm{BiuH}$ and AtzE-dependent reactions. GDH catalyzes the $\mathrm{NADH}$-dependent amination of $\alpha$-ketoglutarate. Ammonia production by BiuH and AtzE was followed using the decrease of absorbance by UV spectrophotometry at $340 \mathrm{~nm}$ that was due to the oxidation of NADH by GDH. 1.25 units of GDH were used in a $250-\mu l$ reaction volume, and the final concentrations of $\alpha$-ketoglutarate and NADH were 3.5 and $0.2 \mathrm{~mm}$, respectively (Fig. S3) (13).

Monitoring the AtzE activity during purification steps from Pseudomonas sp. strain ADP was initially done with its reported substrate, biuret $(1,5,13)$. However, as no ammonia could be detected, the fractions were supplemented with $5.1 \mathrm{~nm}$ AtzD and $0.2 \mathrm{~mm}$ cyanuric acid, in $25 \mathrm{~mm}$ phosphate buffer, $\mathrm{pH} 9$, to generate the substrate in situ. There was a significant background of ammonia in the early steps/cruder fractions; however, AtzE-dependent ammonia production was detectable after the background rate (measured in the absence of cyanuric acid) had been subtracted.

Steady-state kinetics for AtzD were obtained by using $41 \mathrm{nM}$ AtzD, in the presence of various amounts of cyanuric acid substrate ranging from 0 to $0.6 \mathrm{~mm}$. Cyanuric acid degradation was measured by following the decrease in absorbance at $214 \mathrm{~nm}$, but above $0.2 \mathrm{~mm}$ AtzD activity was inhibited. To determine whether the substrate or the product was inhibiting AtzD activity, we pooled $41 \mathrm{~nm}$ AtzD, $24 \mathrm{~nm}$ AtzE, and 5 units/ $\mu$ l GDH in the presence of $0-0.6 \mathrm{~mm}$ cyanuric acid. This removed the inhibition previously observed at cyanuric acid concentrations above $0.2 \mathrm{~mm}$ and allowed for the determination of steady-state kinetics for AtzD. Steady-state kinetics for AtzD were determined using $41 \mathrm{~nm}$ AtzD, 24 nм AtzE, and 5 units/ $\mu$ l GDH, after ensuring that in these proportions the AtzD-mediated reaction was the rate-limiting reaction and with the assumption that the rate of ammonia production recorded was proportional to the AtzD activity rate.

Steady-state kinetics for AtzE with the product of AtzD or barbituric acid hydrolase (BAH) were obtained under conditions where the AtzE-mediated reaction was the rate-limiting reaction (i.e. 3.5 times slower than either the GDH, AtzD, or barbituric acid hydrolase-mediated reactions). AtzE steadystate kinetics were obtained by using $41 \mathrm{~nm}$ AtzD/48 nм barbituric acid hydrolase, $12 \mathrm{~nm}$ AtzE, and 5 units/ $\mu$ l GDH. Substrate (cyanuric acid or barbituric acid) was added over the range of 0-0.6 mM. As AtzE was rate-limiting, it was assumed to be a good estimate of the rate of AtzE.

Other potential AtzE substrates tested were as follows: 1-nitrobiuret; 1-carboxymalonamide; succinamic acid; 2-amino-3ureidopropionic (Albizziin); citrulline; lysine; glutamine; asparagine; biuret; and malonamide. Specific activities were obtained with 12-400 nм AtzE and 5 units/ $\mu$ l GDH and $1.5 \mathrm{~mm}$ substrates in $25 \mathrm{~mm}$ phosphate buffer, $\mathrm{pH}$ 9. Steady-state kinetics were obtained with 1-nitrobiuret using $12 \mathrm{~nm}$ AtzE and 5 units/ $\mu$ l GDH. Substrate, 1-nitrobiuret, was added over the range of 0-2.5 $\mathrm{mm}$. Steady-state kinetics were obtained with 1-carboxy-malonamide using $12 \mathrm{~nm}$ AtzE, $48 \mathrm{~nm} \mathrm{BAH,} \mathrm{and} 5$ units/ $\mu$ l GDH. Substrate (barbituric acid) was added over the range of $0-4 \mathrm{mM}$.

Biuret hydrolase kinetic data were obtained by using $11 \mathrm{nM}$ biuret hydrolase and 5 units/ $\mu \mathrm{l} \mathrm{GDH}$ in the presence of various amounts of biuret ranging from 0 to $0.7 \mathrm{~mm}$. All the kinetics constants were calculated with Hyper32 software, fitting the rate data to Michaelis-Menten Equation 1, 


$$
\frac{\mathrm{d}[P]}{\mathrm{d} t}=\frac{V_{\max }[\mathrm{S}]}{K_{m}+[\mathrm{S}]}
$$

The steady-state kinetic values for AtzE with 1-nitro-biuret were estimated using Lineweaver-Burk Equation 2,

$$
\frac{1}{V_{0}}=\frac{K_{m}}{V_{\max }} \frac{1}{[\mathrm{~S}]}+\frac{1}{V_{\max }}
$$

LC-MS/MS multiple reaction monitoring (MRM)-based enzyme assay was used to follow the fate of cyanuric acid and biuret when in the presence of either BiuH, AtzD, and/or AtzE. Reaction samples were run in triplicate. Four reactions were composed of the following: $10 \mathrm{~mm}$ biuret with $580 \mathrm{~nm} \mathrm{BiuH,} 10$ mm biuret with $374 \mathrm{~nm}$ AtzE, $10 \mathrm{~mm}$ cyanuric acid with $420 \mathrm{~nm}$ AtzD, and $10 \mathrm{~mm}$ cyanuric acid with $420 \mathrm{~nm}$ AtzD and 374 nм AtzE. $5 \mu$ l of reaction mix was injected every 2 min for 30-60 min. Analysis was performed using a Waters Alliance 2695 separation module coupled to a Waters TQD detector, but injections were made using a manual injector with a 5- $\mu$ l injection loop. The HPLC column used was a Phenomenex Develosil RPAQEOUS-AR 5u C30 (dimension: $250 \times 4.6 \mathrm{~mm}$ ), which was heated to $35^{\circ} \mathrm{C}$. A flow rate of $0.7 \mathrm{ml} / \mathrm{min}$ was used (15:1 flow splitter was used after separation). The eluent used was $15 \%(\mathrm{v} / \mathrm{v})$ acetonitrile and $0.1 \%$ formic acid in water. Two simultaneous but independent MRM analyses were performed as follows: MRM parameters for biuret (parent $\mathrm{m} / \mathrm{z}=$ 103.9424): channel 1 (ES+): daughter $(\mathrm{m} / z)$ : 17.9654 , dwell $(\mathrm{s})$ : 0.025 , cone $(\mathrm{V}): 20$, collision $(\mathrm{V})$ : 10 ; and channel $2(\mathrm{ES}+)$ : daughter $(m / z): 43.8956$, dwell (s): 0.025, cone (V): 20, collision (V): 20. MRM parameters for cyanuric acid (parent $\mathrm{m} / \mathrm{z}=$ 127.8577) were channel 1 (ES - ): daughter $(m / z): 41.9357$, dwell (s): 0.025 , cone $(\mathrm{V}): 28$, collision $(\mathrm{V}): 14$. MRM peaks were integrated using Waters MassLynx version 4.1 software.

\section{Proteomics}

In-gel digestion was performed by resuspending pieces of bis-acrylamide gel containing 50-100 $\mu \mathrm{g}$ of protein in $100 \mu \mathrm{l}$ of $25 \mathrm{~mm}$ ammonium bicarbonate. After addition of $5 \mu \mathrm{l}$ of $15 \%$ DTT, the mix was incubated at room temperature for $30 \mathrm{~min}$, followed by addition of $3.5 \mu \mathrm{l}$ of $40 \%$ acrylamide and another 30 min incubation at room temperature. The sample was digested with $0.5 \mu \mathrm{g}$ of trypsin at $37^{\circ} \mathrm{C}$ overnight. To stop the digestion, formic acid was added to a final concentration of $0.1-1 \%$ and then the trypsin-digested peptides were eluted from gel pieces by sonication for $15 \mathrm{~min}$ and further incubated at room temperature for $30 \mathrm{~min}$. Typically, 1-5 $\mu \mathrm{l}$ of sample was used for LC-MS analysis.

The trypsin-digested peptides were separated by reversedphase HPLC using an Agilent NanoFlow LC system (1260 Infinity). The peptides were loaded onto a NanoLC trap column (3 $\mu \mathrm{m}$, ChromXP C18CL, $120 \AA 0.5 \mathrm{~mm} \times 350 \mu \mathrm{m}$ from Eksignet Technologies) by autosampler at a flow rate of $5 \mu \mathrm{l} / \mathrm{min}$ and continuously desalted for $5 \mathrm{~min}$. The desalted peptides were eluted from the trap column and separated on a NanoLC column (3 $\mu \mathrm{m}$, ChromXP C18CL, $120 \AA$, $15 \mathrm{~cm} \times 75 \mu \mathrm{m}$ from Eksigent) with a $0-40 \%$ gradient in 100 min consisting of buffer
A ( $0.1 \%$ formic acid in water) and buffer B $(0.1 \%$ formic acid in acetonitrile). The flow rate of Nano pump was set to $300 \mathrm{nl} / \mathrm{min}$.

Peptides were analyzed using positive and high-sensitive mode on an AB Sciex Tripletof 5500 mass spectrometer. The voltage of Nano Spray II was set to $2300 \mathrm{kV}$. In data-dependent acquisition mode, the mass window for precursor ions of the quadrupole mass analyzer was set to $\pm 1 \mathrm{~m} / \mathrm{z}$. The precursor irons were fragmented by nitrogen collision gas. The MS1 survey scan (250 ms; mass 350-1500) was carried out. 50 of the most abundant precursors were selected for MS/MS scan (50 ms; mass 100-1800). MS/MS spectra were obtained for product ions that had a charge state of 2-5 and were above 10 counts/s. Rolling collision energy was used, and automatic calibration was carried out after every five sample runs.

Mass spectrum data were analyzed using the Paragon algorithm of ProteinPilot (AB Sciex). The detected protein threshold was set to $>0.05(10 \%)$. The matching peptide sequences were identified against the Pseudomonas sp. ADP proteome found in Uniprot. The false discovery rate (FDR) analysis tool algorithm of ProteinPilot provided a global FDR of $1 \%$ and a local FDR at $1 \%$ in all cases.

PPDI-treated AtzE samples were digested with trypsin using the SP3 digestion protocol (34). Peptides were separated using an UltiMate nanoUPLC system, utilizing a 60-min gradient on an Acclaim Pepmap 100 column $(25 \mathrm{~cm} \times 75 \mu \mathrm{m}$ inner diameter with 3- $\mu \mathrm{m}$ particles). High-resolution MS/MS data were obtained on an Orbitrap Fusion Lumos mass spectrometer and top 20 multiply charged species selected for fragmentation in high-high mode with the Orbitrap resolution set at 75,000.

Orbitrap MS/MS data were searched against a focused decoy database containing AtzE, E. coli, and common contaminant protein sequences using the Byonic search engine (Protein Metrics) with tolerance of $5 \mathrm{ppm}$ for precursor ions and $10 \mathrm{ppm}$ for product ions. Enzyme specificity was tryptic and allowed for up to two missed cleavages per peptide. Variable modifications were set for $\mathrm{N}$-terminal acetylation or protein $\mathrm{N}$ termini, oxidation of methionine or tryptophan, deamidation of asparagine or glutamine, and dehydration of cysteine. A Wildcard search with a range of +75 to +80 Da facilitated confident peptide identification ( $<1 \%$ FDR) and spectrum counting of monoaminophosphate- or diaminophosphate-modified serine residues.

\section{Crystallization and structural determination}

The stability of purified AtzE in the phosphate buffer used in the size-exclusion chromatography was assessed using differential scanning fluorimetry as implemented in the Collaborative Crystallisation Centre (35). Protein was used at $2.3 \mathrm{mg} / \mathrm{ml}$ and showed a $T_{m}$ of $64.6 \pm 1.4{ }^{\circ} \mathrm{C}$ in the phosphate buffer, but it also showed that the protein was equally stable in all buffers tested with $\mathrm{pH}$ between 6.5 and 8.5 , and the stability was essentially independent of salt concentration. An initial bank of 384 crystallization trials (PACT, shotgun and PS gradient at $20^{\circ} \mathrm{C}$, shotgun at $8{ }^{\circ} \mathrm{C}$; see http://www.csiro.au/C $3^{4}$ for details of the screens) showed the formation of crystals overnight in many PEG-containing conditions. All of the crystals were small and

\footnotetext{
${ }^{4}$ Please note that the $\mathrm{JBC}$ is not responsible for the long-term archiving and maintenance of this site or any other third party hosted site.
} 


\section{Evolution of AtzE, a 1-carboxybiuret hydrolase}

rod-shaped, and all diffracted poorly and had a pathological packing problem, which made them unsuitable for diffraction analyses. Over the course of a year, over 10,000 droplets were set up, trying various combinations of seeding, in situ proteolysis, concentrations, differing formulations, vapor diffusion, microbatch, and temperatures. All crystals showed the same pathological form as the original crystals that grew overnight. Finally, it was found that the addition of $0.05 \%$ agarose to the protein solution before setup, coupled with seeding from the poor form crystals gave a new crystal form that showed diffraction to $2 \AA$, and did not have the same packing problems. The well-behaved crystal form appeared overnight and grew to full size in 5 days and grew at both 8 and $20^{\circ} \mathrm{C}$. The crystals used in the structural determination were grown from sitting drop trials with $250 \mathrm{nl}$ of $1.1 \mathrm{mg} / \mathrm{ml}$ protein in $25 \mathrm{~mm}$ Hepes, $\mathrm{pH} 7.5,100$ $\mathrm{mM} \mathrm{NaCl}$, with $0.05 \%$ agarose, $250 \mathrm{nl}$ of crystallant $(0.1 \mathrm{M}$ bistris, pH 6.04, $0.276 \mathrm{M} \mathrm{MgCl}_{2}, 17.6 \% \mathrm{w} / \mathrm{v}$ PEG 8000), incubated at $8{ }^{\circ} \mathrm{C}$. Crystals of the protein treated with inhibitor PPDI grew under similar conditions to the native protein (reservoir $0.1 \mathrm{M}$ bis-tris, pH 5.46, $0.128 \mathrm{M} \mathrm{MgCl}_{2}, 21 \% \mathrm{w} / \mathrm{v}$ PEG 8000) at $20^{\circ} \mathrm{C}$. A crystal of the protein-PPDI complex was cryoprotected with reservoir solution supplemented with glycerol to $20 \%$ final concentration and flash-cooled in liquid nitrogen. This crystal was used to collect $360^{\circ}$ of data to $2.1 \AA$ at beamline MX1 of the Australian Synchrotron. The data were initially processed with XDS (36), and the structure was solved by molecular replacement using MoRDa (37), which output two copies each of the A domains from 3ip4 and 3dha in the asymmetric unit. After some rebuilding, the new model was used in Phaser with reprocessed data (using Xia2 and DIALS) (38-42), and this was followed by manual building (COOT) and refinement with Refmac (43). Two complete chains of AtzE (residues 1-457) were located in the asymmetric unit. Additional protein density was clearly visible in the maps, and another protein chain was modeled into the density. The sequence was confirmed by searching the Pseudomonas database and finding that the AtzG sequence matched the sequence of the density (with 66 of 68 residues visible). Subunit interactions were analyzed using PISA (23).

A crystal of the native AtzE without inhibitor was harvested, and data were collected that extended to just beyond $2 \AA$ at the MX2 beamline of the Australian Synchrotron. These data were processed using Xia2/DIALS, and the AtzE/PPDI model was used to phase the data with Phaser.

\section{Computational methods}

Models of AtzEG containing biuret and 1-carboxybiuret were prepared in Accelrys Discovery Studio version 4.1 using the experimentally derived structure as a starting point. Models for the substrates were relaxed using the Full Minimization tool in Discovery Studio version 4.1 using the default settings (CHARMm force field) and positioned in the receptor cavity (active site) using CDOCKER with the default parameters.

Ligands were prepared for MD using the Antechamber module in AMBER16 (44) using the GAFF2 force field. The protein models were prepared for MD simulations using xLeap applying the ff14SB force field and charge-neutralized by the addition of $\mathrm{Na}^{+}$ions. The proteins were solvated in a TIP3P-trun- cated octahedral solvent box with a minimum $12-\AA ̊$ periodic boundary distance from the solute.

Initial minimization of both systems was performed using AMBER 16 over 10,000 steps under a constant pressure of 1 bar (Berendsen barostat). Bonds lengths on bonds involving hydrogen were constrained using SHAKE, and force evaluation on these bonds was not performed. MD simulations of 500 ns with a stepsize of $0.002 \mathrm{ps}$ were performed at $310 \mathrm{~K}$ and 1 bar pressure with a 1-ps relaxation time. Long range electrostatic interactions were treated with the particle mesh Ewald method beyond 12 A. Simulations were analyzed using VMD (version 1.9.2) (45).

Molecular Mechanics Poisson-Boltzmann Surface Area (MMPBSA) continuum solvation models were calculated using the MM-PBSA module in AMBER 16 over the course of the entire simulation. Entropy approximations were calculated with ptraj.

The ammonia tunnel in the GatCAB complex (PDB code $2 \mathrm{G} 5 \mathrm{H}$ ) and the equivalent tunnel in AtzEG were visualized using CAVER 3 (30) using the default parameters (clustering threshold of 3.5; probe radius of 0.9; approximation of 12).

Author contributions-L. E., T. S.P., M. W., J.-W. L., H. O., T. N., and J. N. formal analysis; L. E., T. S. P., M. W., J.-W. L., N. G. F., H. O., T. N., and J. N. investigation; L. E., T. S. P., J. N., and C. S. writing-original draft; L. E., T. S. P., C. J. H., C. J. E., J. N., and C. S. writing-review and editing; M. W., C. J. H., C. J. E., and C. S. supervision; J. N. data curation; C. S. conceptualization; C. S. funding acquisition; C. S. project administration.

Acknowledgments-We thank the beamline scientists at the Australian Synchrotron for their help in data collection. Crystals were grown in the CSIRO Collaborative Crystallisation Centre (http://www. csiro.au/C3) ${ }^{4}$ at CSIRO Manufacturing. We also thank Drs. Andrew Warden and Thomas Walsh (CSIRO Land E Water) for their constructive comments while preparing this manuscript.

\section{References}

1. Cameron, S. M., Durchschein, K., Richman, J. E., Sadowsky, M. J., and Wackett, L. P. (2011) A new family of biuret hydrolases involved in $s$-triazine ring metabolism. ACS Catal. 2011, 1075-1082 Medline

2. Udiković-Kolić, N., Scott, C., and Martin-Laurent, F. (2012) Evolution of atrazine-degrading capabilities in the environment. Appl. Microbiol. Biotechnol. 96, 1175-1189 CrossRef Medline

3. Jutzi, K., Cook, A. M., and Hutter, R. (1982) The degradative pathway of the $s$-triazine melamine: the steps to ring cleavage. Biochem. J. 208, 679-684 Medline

4. Mandelbaum, R. T., Allan, D. L., and Wackett, L. P. (1995) Isolation and characterization of a Pseudomonas sp that mineralizes the $s$-triazine herbicide atrazine. Appl. Environ. Microbiol. 61, 1451-1457 Medline

5. Martinez, B., Tomkins, J., Wackett, L. P., Wing, R., and Sadowsky, M. J. (2001) Complete nucleotide sequence and organization of the atrazine catabolic plasmid pADP-1 from Pseudomonas sp. strain ADP. J. Bacteriol. 183, 5684-5697 CrossRef Medline

6. de Souza, M. L., Wackett, L. P., Boundy-Mills, K. L., Mandelbaum, R. T., and Sadowsky, M. J. (1995) Cloning, characterization, and expression of a gene region from Pseudomonas sp. strain ADP involved in the dechlorination of atrazine. Appl. Environ. Microbiol. 61, 3373-3378 Medline

7. Peat, T. S., Newman, J., Balotra, S., Lucent, D., Warden, A. C., and Scott, C. (2015) The structure of the hexameric atrazine chlorohydrolase AtzA. Acta Crystallogr D Biol. Crystallogr. 71, 710-720 CrossRef Medline

8. Seffernick, J. L., Aleem, A., Osborne, J. P., Johnson, G., Sadowsky, M. J., and Wackett, L. P. (2007) Hydroxyatrazine $N$-ethylaminohydrolase (AtzB): an 


\section{Evolution of AtzE, a 1-carboxybiuret hydrolase}

amidohydrolase superfamily enzyme catalyzing deamination and dechlorination. J. Bacteriol. 189, 6989-6997 CrossRef Medline

9. Balotra, S., Warden, A. C., Newman, J., Briggs, L. J., Scott, C., and Peat, T. S. (2015) X-ray structure and mutagenesis studies of the $N$-isopropylammelide isopropylaminohydrolase, AtzC. PLoS ONE 10, e0137700 CrossRef Medline

10. Sadowsky, M. J., Tong, Z., de Souza, M., and Wackett, L. P. (1998) AtzC is a new member of the amidohydrolase protein superfamily and is homologous to other atrazine-metabolizing enzymes. J. Bacteriol. 180, 152-158 Medline

11. Peat, T. S., Balotra, S., Wilding, M., French, N. G., Briggs, L. J., Panjikar, S., Cowieson, N., Newman, J., and Scott, C. (2013) Cyanuric acid hydrolase: evolutionary innovation by structural concatenation. Mol. Microbiol. 88, 1149-1163 CrossRef Medline

12. Peat, T. S., Balotra, S., Wilding, M., Hartley, C. J., Newman, J., and Scott, C. (2017) High-resolution X-ray structures of two functionally distinct members of the cyclic amide hydrolase family of Toblerone fold enzymes. Appl. Environ. Microbiol. 83, e03365-16 Medline

13. Balotra, S., Newman, J., Cowieson, N. P., French, N. G., Campbell, P. M., Briggs, L. J., Warden, A. C., Easton, C. J., Peat, T. S., and Scott, C. (2015) $\mathrm{X}$-ray structure of the amidase domain of AtzF, the allophanate hydrolase from the cyanuric acid-mineralizing multienzyme complex. Appl. Environ. Microbiol. 81, 470-480 CrossRef Medline

14. Cheng, G., Shapir, N., Sadowsky, M. J., and Wackett, L. P. (2005) Allophanate hydrolase, not urease, functions in bacterial cyanuric acid metabolism. Appl. Environ. Microbiol. 71, 4437-4445 CrossRef Medline

15. Shapir, N., Sadowsky, M. J., and Wackett, L. P. (2005) Purification and characterization of allophanate hydrolase (AtzF) from Pseudomonas sp. strain ADP. J. Bacteriol. 187, 3731-3738 CrossRef Medline

16. Eaton, R. W., and Karns, J. S. (1991) Cloning and comparison of the DNA encoding ammelide aminohydrolase and cyanuric acid amidohydrolase from three s-triazine-degrading bacterial strains. J. Bacteriol. 173, 1363-1366 CrossRef Medline

17. Seffernick, J. L., Erickson, J. S., Cameron, S. M., Cho, S., Dodge, A. G., Richman, J. E., Sadowsky, M. J., and Wackett, L. P. (2012) Defining sequence space and reaction products within the cyanuric acid hydrolase (AtzD)/barbiturase protein family. J. Bacteriol. 194, 4579 - 4588 CrossRef Medline

18. Balotra, S., Newman, J., French, N. G., Briggs, L. J., Peat, T. S., and Scott, C. (2014) Crystallization and preliminary X-ray diffraction analysis of the amidase domain of allophanate hydrolase from Pseudomonas sp. strain ADP. Acta Crystallogr F Struct. Biol. Commun. 70, 310-315 CrossRef Medline

19. Esquirol, L., Peat, T. S., Wilding, M., Lucent, D., French, N. G., Hartley, C. J., Newman, J., and Scott, C. (2018) Structural and biochemical characterization of the biuret hydrolase (BiuH) from the cyanuric acid catabolism pathway of Rhizobium leguminasorum bv. viciae 3841. PLOS ONE 13, e0192736 CrossRef Medline

20. Berman, H. M., Westbrook, J., Feng, Z., Gilliland, G., Bhat, T. N., Weissig, H., Shindyalov, I. N., and Bourne, P. E. (2000) The Protein Data Bank. Nucleic Acids Res. 28, 235-242 Medline

21. Suzuki, T., Nakamura, A., Kato, K., Söll, D., Tanaka, I., Sheppard, K., and Yao, M. (2015) Structure of the Pseudomonas aeruginosa transamidosome reveals unique aspects of bacterial tRNA-dependent asparagine biosynthesis. Proc. Natl. Acad. Sci. U.S.A. 112, 382-387 CrossRef Medline

22. Nakamura, A., Yao, M., Chimnaronk, S., Sakai, N., and Tanaka, I. (2006) Ammonia channel couples glutaminase with transamidase reactions in GatCAB. Science 312, 1954-1958 CrossRef Medline

23. Krissinel, E., and Henrick, K. (2007) Inference of macromolecular assemblies from crystalline state. J. Mol. Biol. 372, 774-797 CrossRef Medline

24. Curnow, A. W., Hong, Kw., Yuan, R., Kim, Si., Martins, O., Winkler, W., Henkin, T. M., and Söll, D. (1997) Glu-tRNA(Gln) amidotransferase: a novel heterotrimeric enzyme required for correct decoding of glutamine codons during translation. Proc. Natl. Acad. Sci. U.S.A. 94, 11819-11826 CrossRef Medline

25. Skouloubris, S., Ribas de Pouplana, L., De Reuse, H., and Hendrickson, T. L. (2003) A noncognate aminoacyl-tRNA synthetase that may resolve a missing link in protein evolution. Proc. Natl. Acad. Sci. U.S.A. 100, 11297-11302 CrossRef Medline
26. Shin, S., Lee, T. H., Ha, N. C., Koo, H. M., Kim, S. Y., Lee, H. S., Kim, Y. S., and Oh, B. H. (2002) Structure of malonamidase E2 reveals a novel SercisSer-Lys catalytic triad in a new serine hydrolase fold that is prevalent in nature. EMBO J. 21, 2509-2516 CrossRef Medline

27. Paetzel, M., Dalbey, R. E., and Strynadka, N. C. (1998) Crystal structure of a bacterial signal peptidase in complex with a $\beta$-lactam inhibitor. Nature 396, 186-190 CrossRef Medline

28. Peat, T. S., Frank, E. G., McDonald, J. P., Levine, A. S., Woodgate, R., and Hendrickson, W. A. (1996) Structure of the UmuD' protein and its regulation in response to DNA damage. Nature 380, 727-730 CrossRef Medline

29. de Souza, M. L., Wackett, L. P., and Sadowsky, M. J. (1998) The atzABC genes encoding atrazine catabolism are located on a self-transmissible plasmid in Pseudomonas sp. strain ADP. Appl. Environ. Microbiol. 64, 2323-2326 Medline

30. Pavelka, A., Sebestova, E., Kozlikova, B., Brezovsky, J., Sochor, J., and Damborsky, J. (2016) CAVER: Algorithms for analyzing dynamics of tunnels in macromolecules. IEEE-ACM Trans. Comput. Biol. Bioinform. 13, 505-517 CrossRef Medline

31. Min, B., Pelaschier, J. T., Graham, D. E., Tumbula-Hansen, D., and Söll, D. (2002) Transfer RNA-dependent amino acid biosynthesis: an essential route to asparagine formation. Proc. Natl. Acad. Sci. U.S.A. 99, 2678-2683 CrossRef Medline

32. Baek, J., Lee, J., Yoon, K., and Lee, H. (2017) Identification of unannotated small genes in Salmonella. G3 7, 983-989 CrossRef Medline

33. Hücker, S. M., Ardern, Z., Goldberg, T., Schafferhans, A., Bernhofer, M., Vestergaard, G., Nelson, C. W., Schloter, M., Rost, B., Scherer, S., and Neuhaus, K. (2017) Discovery of numerous novel small genes in the intergenic regions of the Escherichia coli O157:H7 Sakai genome. PLoS ONE 12, e0184119 CrossRef Medline

34. Hughes, C. S., Foehr, S., Garfield, D. A., Furlong, E. E., Steinmetz, L. M., and Krijgsveld, J. (2014) Ultrasensitive proteome analysis using paramagnetic bead technology. Mol. Syst. Biol. 10, 757 CrossRef Medline

35. Rosa, N., Ristic, M., Seabrook, S. A., Lovell, D., Lucent, D., and Newman, J. (2015) Meltdown: a tool to help in the interpretation of thermal melt curves acquired by differential scanning fluorimetry. J. Biomol. Screen. 20, 898-905 CrossRef Medline

36. Kabsch, W. (2010) XDS. Acta Crystallogr D Biol Crystallogr 66, 125-132 CrossRef Medline

37. Winn, M. D., Ballard, C. C., Cowtan, K. D., Dodson, E. J., Emsley, P., Evans, P. R., Keegan, R. M., Krissinel, E. B., Leslie, A. G., McCoy, A., McNicholas, S. J., Murshudov, G. N., Pannu, N. S., Potterton, E. A., Powell, H. R., et al. (2011) Overview of the CCP4 suite and current developments. Acta Crystallogr D Biol Crystallogr 67, 235-242 CrossRef Medline

38. McCoy, A. J., Grosse-Kunstleve, R. W., Adams, P. D., Winn, M. D., Storoni, L. C., and Read, R. J. (2007) Phaser crystallographic software. J. Appl. Crystallogr. 40, 658-674. CrossRef Medline

39. McCoy, A. J. (2007) Solving structures of protein complexes by molecular replacement with Phaser. Acta Crystallogr. D Biol. Crystallogr. 63, 32-41 CrossRef Medline

40. Parkhurst, J. M., Winter, G., Waterman, D. G., Fuentes-Montero, L., Gildea, R. J., Murshudov, G. N., and Evans, G. (2016) Robust background modelling in DIALS. J. Appl. Crystallogr. 49, 1912-1921 CrossRef Medline

41. Waterman, D. G., Winter, G., Gildea, R. J., Parkhurst, J. M., Brewster, A. S., Sauter, N. K., and Evans, G. (2016) Diffraction-geometry refinement in the DIALS framework. Acta Crystallogr D Struct. Biol. 72, 558-575 CrossRef Medline

42. Winter, G. (2010) xia2: an expert system for macromolecular crystallography data reduction. J. Appl. Cryst. 43, 186-190 CrossRef

43. Murshudov, G. N., Vagin, A. A., and Dodson, E. J. (1997) Refinement of macromolecular structures by the maximum-likelihood method. Acta Crystallogr. D Biol. Crystallogr. 53, 240-255 CrossRef Medline

44. Case, D. A., Cerutti, D. S., Cheatham, I., Darden, R. E., Duke, T. J., Giese T. J., Gohlke, H., Goetz, A. W., Greene, D., Homeyer, N., Izadi, S., Kovalenko, A., Lee, T. S., LeGrand, S., Li, P., et al. (2017) AMBER16, University of California, San Francisco, CA

45. Humphrey, W., Dalke, A., and Schulten, K. (1996) VMD: visual molecular dynamics. J. Mol. Graph. 14, 33-38, 27-8 CrossRef Medline 